\title{
Essential Role of the cVRG in the Generation of Both the Expiratory and Inspiratory Components of the Cough Reflex
}

\author{
Elenia CINELLI ${ }^{1}$, Ludovica IOVINO ${ }^{1}$, Fulvia BONGIANNI ${ }^{1}$, Tito PANTALEO ${ }^{1}$, Donatella \\ MUTOLO $^{1}$
}

${ }^{1}$ Department of Experimental and Clinical Medicine, Physiological Sciences Section, University of Florence, Florence, Italy

Received July 8, 2019

Accepted September 9, 2019

\section{Summary}

As stated by Korpáš and Tomori (1979), cough is the most important airway protective reflex which provides airway defensive responses to nociceptive stimuli. They recognized that active expiratory efforts, due to the activation of caudal ventral respiratory group (cVRG) expiratory premotoneurons, are the prominent component of coughs. Here, we discuss data suggesting that neurons located in the CVRG have an essential role in the generation of both the inspiratory and expiratory components of the cough reflex. Some lines of evidence indicate that CVRG expiratory neurons, when strongly activated, may subserve the alternation of inspiratory and expiratory cough bursts, possibly owing to the presence of axon collaterals. Of note, experimental findings such as blockade or impairment of glutamatergic transmission to the cVRG neurons lead to the view that neurons located in the CVRG are crucial for the production of the complete cough motor pattern. The involvement of bulbospinal expiratory neurons seems unlikely since their activation affects differentially expiratory and inspiratory muscles, while their blockade does not affect baseline inspiratory activity. Thus, other types of CVRG neurons with their medullary projections should have a role and possibly contribute to the fine tuning of the intensity of inspiratory and expiratory efforts.

\section{Key words}

Caudal ventral respiratory group - Expiratory bulbospinal neurons $\bullet$ Cough motor pattern generation - Downregulation of the cough reflex $\bullet$ Components of the cough reflex

\section{Corresponding author}

Elenia Cinelli, Dipartimento di Medicina Sperimentale e Clinica, Sezione Scienze Fisiologiche, Università degli Studi di Firenze, Viale G.B. Morgagni 63, 50134 Firenze, Italy. E-mail: elenia.cinelli@unifi.it

\section{Introduction}

As already stated by Korpáš and Tomori (1979) in their very interesting and comprehensive book, cough is the most important defensive reflex of the airways, primarily provoked by the stimulation of the tracheobronchial and laryngeal mucosa. They stressed the importance of "protection and defensive mechanisms of the respiratory system" and considered the exposure of respiratory organs to the action of damaging and harmful agents of the environment. That is, they identified airway defensive reflexes, and in particular cough, as responses to nociceptive stimuli actually or potentially damaging tissues, thus already revealing the possibility of similarities, only recently noted, between neural mechanisms underlying cough and pain both at the peripheral and central levels (Mutolo 2017).

Korpáš and Tomori (1979) also recognized that the most important component of the cough is the active expiratory effort produced by the contraction of expiratory muscles and that the activation of expiratory bulbospinal neurons located in the caudal ventral respiratory group (cVRG), including "latent" or quiescent expiratory neurons under normal breathing conditions, was its physiological correlate, thus advancing the proposal of an essential role of the cVRG located in the nucleus retroambigualis (NRA) in the generation of the expiratory component of this reflex (Fig. 1). Recordings from the cVRG neurons also led to the suggestion that an important "cough centre" was located in this nucleus, but other views were also present (Kasé 1980, for review see 
also Pantaleo et al. 2002, and Korpáš and Tomori 1979). In this short review, we will report and discuss data suggesting that the cVRG is essential for the generation of both the inspiratory and expiratory components of the cough reflex, i.e. for the production of the complete cough motor pattern.

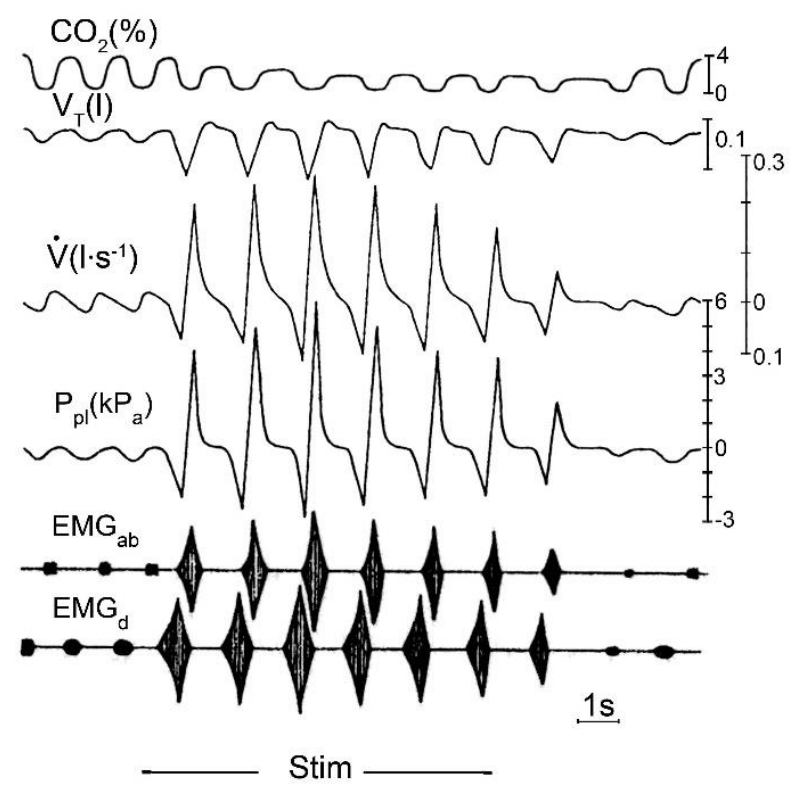

Fig. 1. Changes in various parameters during coughing attack evoked by mechanical stimulation (Stim.) of tracheobronchial mucosa in anaesthetized cats, shown schematically. Recordings: $\mathrm{CO}_{2}(\%)$ - tidal $\mathrm{CO}_{2}$ content; $\mathrm{V}_{\mathrm{T}}$ - tidal volume; $\dot{\mathrm{V}}$ - tracheal airflow; $\mathrm{P}_{\mathrm{pl}}$ - pleural pressure; $\mathrm{EMG}_{\mathrm{ab}}$ - electromyogram of abdominal muscles; $\mathrm{EMG}_{d}$ - electromyogram of diaphragm. Time $1 \mathrm{~s}$. Recordings of tracheal airflow and pleural pressure clearly show that active expiratory efforts produced by expiratory muscles strongly characterize the cough motor pattern (from Korpáš and Tomori 1979).

\section{Neural substrate involved in the generation of the cough reflex}

An overview on the different brainstem structures involved in cough production have been recently provided (Mutolo 2017). Here, it is sufficient to briefly recall that several studies on the behavior of medullary respiratory neurons during coughing have led to the conclusion that the same respiratory neurons involved in the production of the eupneic breathing also have a role in cough motor pattern generation (Oku et al. 1994, Bongianni et al. 1998, Shannon et al. 1996, 2004, Bolser and Davenport 2002, Pantaleo et al. 2002, Baekey et al. 2003, Ott et al. 2011), thus supporting the existence of multifunctional neural networks in the mammalian brainstem and of neurons contributing to different functions.
The central mechanisms underlying breathing imply a respiratory cycle divided into three phases: inspiration, post-inspiration and expiration (e.g. Richter and Smith 2014). Post-inspiratory activity provides the neural substrate to brake the expiratory airflow and is of great importance for the mediation of airway protective reflexes, including cough (Dutschmann and Herbert 2006, Dutschmann et al. 2014). Cough can be considered a modified respiratory act, including the inspiratory phase, the post-inspiratory or compressive phase (glottal closure) and the expiratory or expulsive phase (e.g. Korpáš and Tomori 1979, Widdicombe 1986). Interestingly, recent lines of evidence suggest that rhythmic breathing behavior is generated by discrete, but coupled oscillators in the medulla (e.g. Del Negro et al. 2018, Pisanski and Pagliardini 2018). The preBötzinger Complex (preBötC) is responsible for generating inspiratory rhythm and for coordinating the other phases of the respiratory cycle. The parafacial respiratory group (pFRG) is responsible for active expiration in conditions of increased metabolic demand (exercise, hypoxia, hypercapnia). The Post-inspiratory Complex (PiCo) is considered necessary and sufficient for generating postinspiratory activity in vivo. In conclusion, a "triple oscillator model" has been proposed responsible for breathing activity (Anderson et al. 2016).

\section{Some characteristics of the cVRG (NRA) neurons}

The cVRG is an important site of action of neuroactive chemicals affecting the cough reflex (Mutolo 2017). In this respiration-related medullary region, bulbospinal expiratory neurons (premotoneurons) and other types of expiratory and non-respiratory neurons are located (Arita et al. 1987, Iscoe 1998, Subramanian and Holstege 2009, Subramanian et al. 2018). The neural structures located caudal to the obex within the ventral respiratory column have been considered for a long time to be unnecessary for the genesis of the eucapnic pattern of breathing (e.g. Von Euler 1986, Bianchi et al. 1995, Feldman et al. 2013). In fact, as suggested by morphological and electrophysiological lines of evidence cVRG expiratory neurons do not possess axon collaterals and, as a consequence, connections with other medullary respiratory structures. By contrast, the activation of neurons located in the cVRG via microinjections of excitatory amino acid (EAA) receptor agonists caused transient inhibition of 


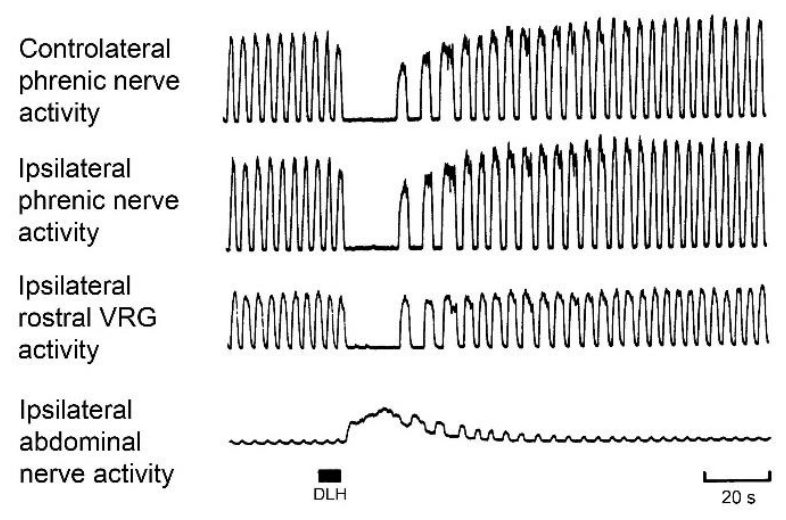

Fig. 2. Changes in inspiratory and expiratory motor output as well as in the activity of inspiratory rostral ventral respiratory group (VRG) neurons in response to $15 \mathrm{nl}$ of $160 \mathrm{mM}$ D,L-homocysteic acid (DLH) injected (filled bar) into the caudal VRG (cVRG). Anaesthetized, paralyzed, vagotomized and artificially ventilated cats. Modified from Bongianni et al. 1994.

inspiratory activity in cats (Bongianni et al. 1994), rats (Bonham and Jeske 1989, Chitravanshi and Sapru 1999) and rabbits (Bongianni et al. 2005). In more details, microinjections of D,L-homocysteic acid (DLH), a broadspectrum EAA receptor agonist, into the cVRG of the cat (Bongianni et al. 1994) induces the activation of expiratory motoneurons (evidence of expiratory premotoneuron involvement) along with a concomitant silent period in phrenic nerve activity (Fig. 2). Similar results have been reported by Poliacek et al. (2007). Recent studies (Subramanian and Holstege 2009, Jones et al. 2016) have analyzed in more detail respiratory effects triggered by EAA receptor stimulation within the NRA region, including the cVRG. Bongianni et al. (1994, see also Iscoe 1998) hypothesized that cVRG neurons may affect the pattern of breathing probably via axon collaterals when strongly activated. The cVRG neuronal population is not homogeneous (Lipski et al. 1984, Arita et al. 1987, Smith et al. 1989, Iscoe 1998, Subramanian and Holstege 2009, Subramanian et al. 2018) and chemical stimulation may bring into action not only respiratory, but also non-respiratory neurons and high threshold respiration-related neurons that possibly have axon collaterals (Iscoe 1998). Massive activation of parent neurons may disclose the effect and the presence of axon collaterals, although rare or characteristic of only a subgroup of neurons. Thus, caudal respiratory neurons, even if not essential for respiratory rhythm generation, could alter the breathing pattern when strongly activated. These considerations could be relevant to airway defensive reflex, such as coughing and sneezing
(Bongianni et al. 1994, Iscoe 1998) where, as a rule, alternating bursts of inspiratory and expiratory activities are present. The presence of cVRG projections to other medullary respiration-related regions and therefore to both inspiratory and expiratory medullary neurons appear to corroborate the present hypothesis (Holstege and Kuypers 1982, Feldman et al. 1985, Holstege 1989, Smith et al. 1989, Gerrits and Holstege 1996, Iscoe 1998, Zheng et al. 1998, Jones et al. 2016).

The afferent projections to the cVRG (NRA) are not definitely assessed. However, their source could be the Bötzinger Complex (BötC), the retrotrapezoid nucleus $(\mathrm{RTN}) / \mathrm{pFRG}$, the limbic system and the periaqueductal gray (for details and Refs. see Mutolo 2017). In this context, it seems appropriate to mention that BötC excitatory projections to the cVRG could have an important role in the generation of the cough motor pattern (e.g. Bongianni et al. 1998, Shannon et al. 2000).

Accordingly, bilateral blockades of BötC regions by means of lignocaine or kainic acid microinjections was found to suppress spontaneous rhythmic expiratory activity as well as both the inspiratory and expiratory components of the cough reflex (Mutolo et al. 2002). At variance with these results, Poliacek et al. (2008) found that DLH-induced unilateral activation of the BötC caused suppressant effects on the cough reflex, in agreement the general inhibitory role of the BötC expiratory neurons (e.g. Merrill et al. 1983, Jiang and Lipski 1990, Ezure 1990, Poliacek et al. 2008 also for further Refs.). The reason of this discrepancy is not clear, but could be ascribed in part to differences in the preparation and experimental procedures, but they may also be due to the fact that the population of BötC neurons is not homogeneous and contains both excitatory and inhibitory subgroups of neurons. In addition, it should also be kept in mind that blockade of a neural substrate is a procedure quite different from its activation.

As to the RTN/pFRG, the activity of the majority of respiratory neurons in this region was changed in synchrony with coughing and swallowing. However, transverse brainstem sections suggested that the neuronal mechanisms essential for coughing are relatively caudal and could involve mainly the caudal nucleus tractus solitarii (NTS) and neighboring inspiratory and expiratory regions of the ventral respiratory column (Sugiyama et al. 2015). In fact, transections caudal to the RTN/pFRG region decreased, but did not abolish cough-related abdominal nerve discharges. In other word, it seems that this region may 
contribute to the expiratory control under normal conditions, but is not a crucial element of the neuronal network underlying coughing or swallowing. Interestingly, some recent report suggests the existence of NRA regions important for respiratory pattern generation (see e.g. Oku et al. 2008, Jones et al. 2012, Ikeda et al. 2017).

\section{Role of the cVRG in the generation of both expiratory and inspiratory components of the cough reflex}

Interestingly, in the study of neurotransmitters involved in determining the excitatory drive to cVRG expiratory neurons, it was found (Bongianni et al. 2005) that the blockade of both NMDA and non-NMDA receptors making use of microinjections of the broadspectrum EAA receptor antagonist kynurenic acid (KYN) and, in particular, of non-NMDA receptors through microinjections of the specific non-NMDA antagonist CNQX into the cVRG completely suppressed not only spontaneous rhythmic abdominal activity and some reflex expiratory responses (Breuer-Hering inflation reflex, expiratory threshold loading), but also both the inspiratory and expiratory components of the cough reflex (Fig. 3). This finding implies that neurons located in the cVRG are not merely elements of the expiratory
Control

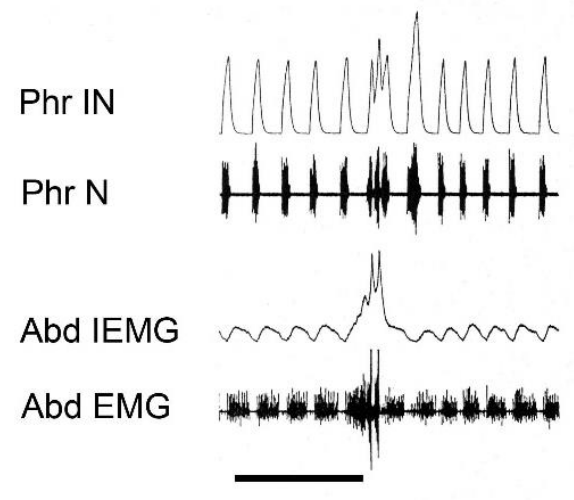

Control

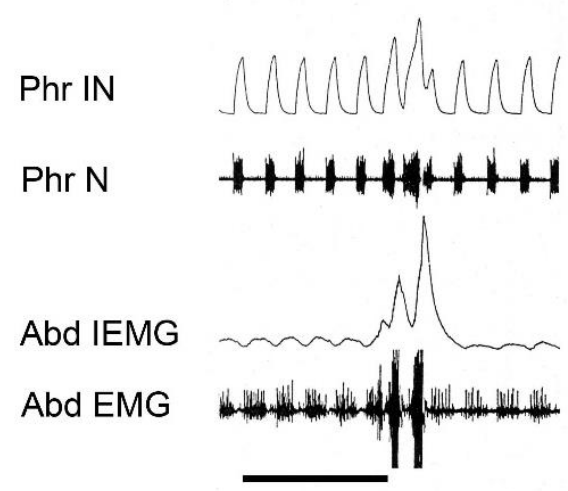

$50 \mathrm{mM} \mathrm{KYN}$
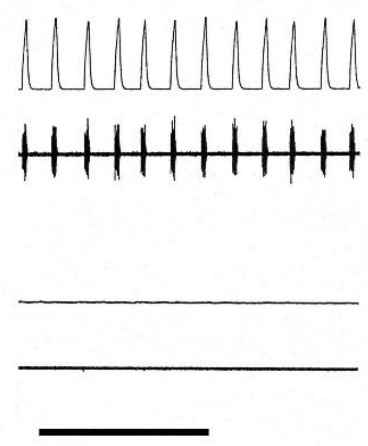

$10 \mathrm{mM} \mathrm{CNQX}$
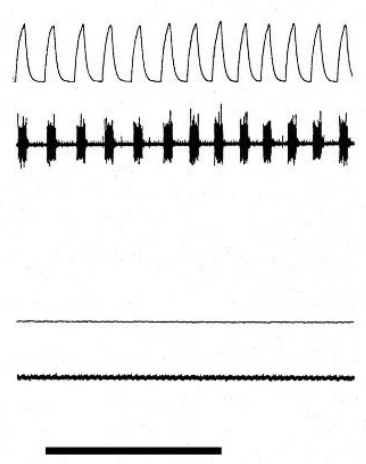

Recovery
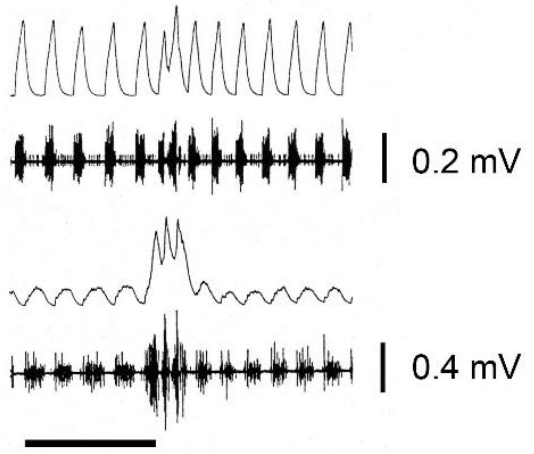

Recovery
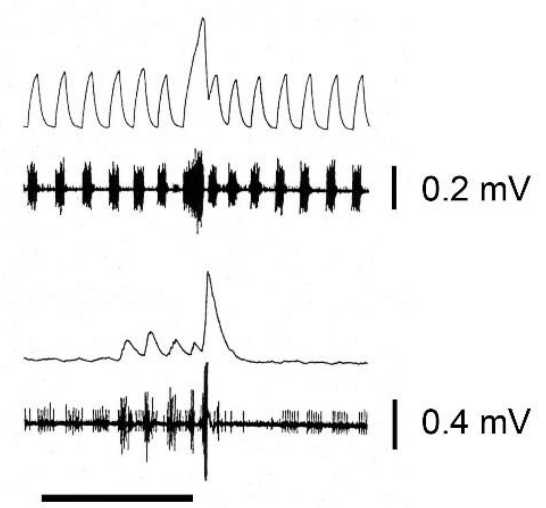

$5 \mathrm{~s}$

Fig. 3. Antagonists of excitatory amino acid (EAA) receptors bilaterally microinjected into the caudal ventral respiratory group (cVRG) caused within 10 min depressant effects on spontaneous rhythmic expiratory activity and on cough reflex responses induced by mechanical stimulation of the tracheobronchial tree. Stimulation periods marked by filled bars. Traces are phrenic integrated neurogram (Phr IN); phrenic neurogram (Phr N); abdominal integrated electromyographic activity (Abd IEMG); abdominal electromyographic activity (Abd EMG). Anaesthetized, spontaneously breathing rabbits. Modified from Bongianni et al. 2005. 
output system, but are crucial for the production of the overall cough motor pattern. It seems relevant to note that the effects of non-NMDA blockade on the inspiratory component cannot be accounted for by the suppression of the excitatory output from cVRG expiratory premotoneurons. As shown by Newson Davis and Plum (1972), bilateral lesions of descending bulbospinal expiratory pathways impair spontaneous rhythmic abdominal activity with minor or no interference with the expiratory component of the cough reflex or other expiratory efforts. That is, separate descending pathways appear to carry the central respiratory drive to inspiratory and expiratory motoneurons, respectively. Similarly, bilateral microinjections of both DAMGO and baclofen at relatively high concentrations (5 and $1 \mathrm{mM}$, respectively), as well as of clonidine $(5 \mathrm{mM})$ and tizanidine $(0.5 \mathrm{mM})$ or muscimol $(0.3 \mathrm{mM})$ into the cVRG led to the complete suppression of the entire cough reflex (Mutolo et al. 2010, Cinelli et al. 2012, 2013). An example of these findings is illustrated in Fig. 4. It is worth mentioning that caudal expiratory neurons have been reported to receive a potent GABAergic inhibition and, accordingly, bilateral microinjections of $1 \mathrm{mM}$ bicuculline into the cVRG not only increased respiratory frequency and abdominal muscle activity, but also potentiated cough reflex responses mainly because of increases in the cough number. Interestingly, strong suppressant effect on both inspiratory and expiratory components of the cough reflex have been reported in the cat following unilateral microinjections of DLH (20-50 mM), codeine (3.3 mM) or nicotine $(5 \mathrm{mM})$ into cVRG (Poliacek et al. 2007, 2010, 2015). These outcomes suggest that a cough suppressant neuronal network may exist in the cVRG directly or indirectly involved in the control of reflex excitability. They do not seem in contrast with our above reported interpretation.

\section{Interpretation and concluding remarks}

The main finding that is highlighted in this short review is that neurons located in the $\mathrm{cVRG}$ have a pivotal role in the generation of both inspiratory and expiratory components of the cough reflex. Taking into consideration the results of lesion experiments performed by Newsom Davis and Plum (1972) it appears clear that descending pathways from cVRG bulbospinal expiratory neurons are unnecessary for the production of the inspiratory component of the cough reflex. However, our findings do not exclude that different types of neurons

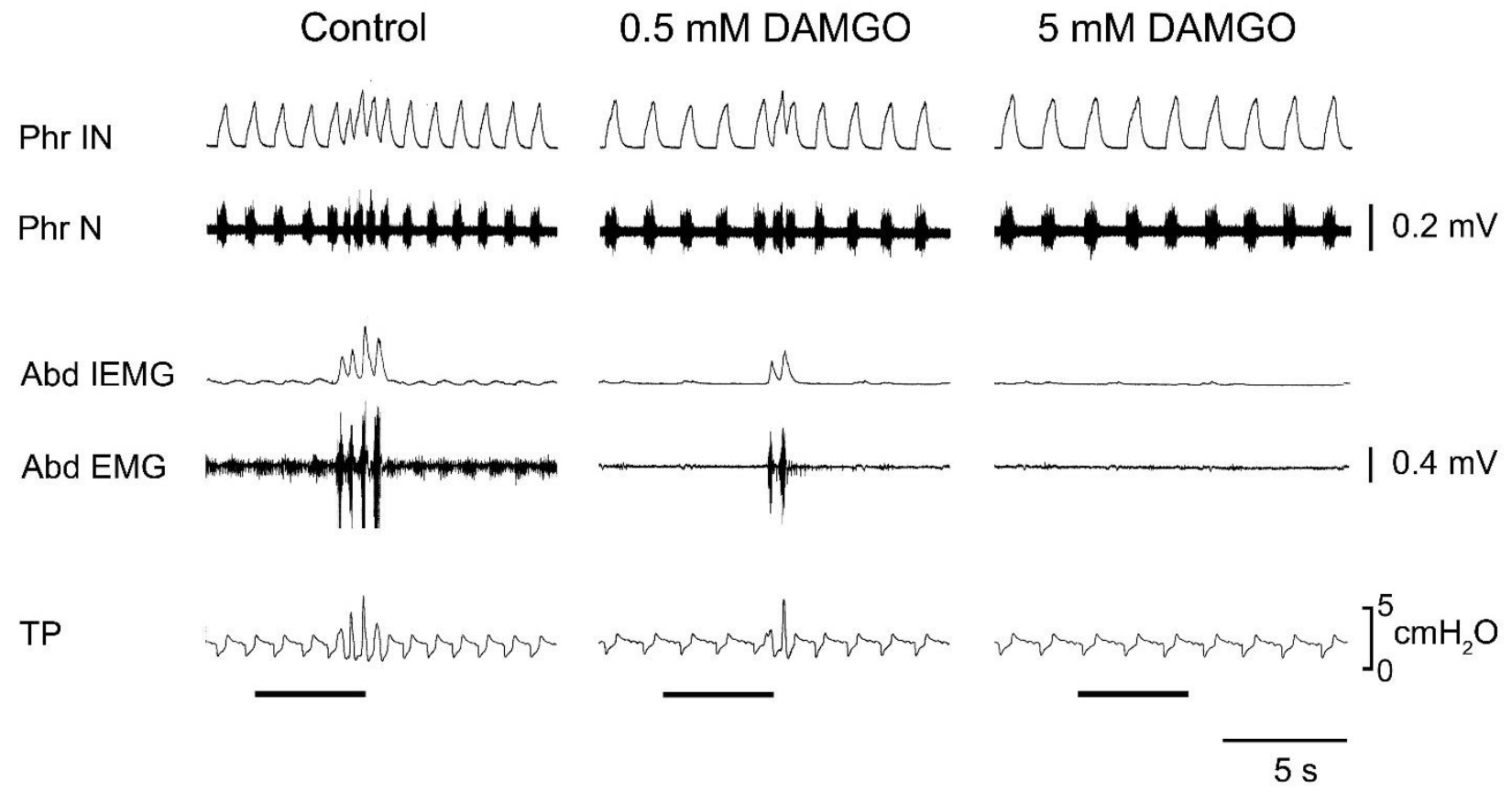

Fig. 4. Effects of 0.5 and $5 \mathrm{mM}$ DAMGO bilaterally microinjected into the caudal ventral respiratory group (cVRG) on baseline respiratory activity and cough reflex responses induced by mechanical stimulation of the tracheobronchial tree. Stimulation periods marked by filled bars. Anaesthetized, spontaneously breathing rabbits. Traces are phrenic integrated neurogram (Phr IN); phrenic neurogram (Phr N); abdominal integrated electromyographic activity (Abd IEMG); abdominal electromyographic activity (Abd EMG); tracheal pressure (TP). Anaesthetized, spontaneously breathing rabbits. Modified from Mutolo et al. 2010. 
located in the cVRG, either respiration-related or nonrespiration-related neurons are involved. As already mentioned, several types of neurons exist in the cVRG that project to and receive from several brainstem areas. These connections may, at least in part, underlie the role of the cVRG in affecting the excitability and even the discharge pattern of medullary inspiratory neurons.

We consider unlikely that expiratory premotoneurons of the cVRG are involved in this effect. In fact, as previously discussed, axon collaterals of expiratory premotor units are few, but probably could affect the breathing pattern when parent neurons are strongly activated. The involvement of bulbospinal expiratory neurons appears unlikely since DLH activation of cVRG neurons causes opposite effects on expiratory and inspiratory muscles. In addition, microinjections of KYN or CNQX into the cVRG produce clear effects on expiratory muscles, but do not affect the activity of the inspiratory bursts of the eucapnic pattern of breathing. Thus, we consider that other types of neurons should have a role.

As already reported, we have shown that cVRG neurons involved in the generation of the inspiratory component of the cough reflex receive a glutamatergic input and possibly also project an excitatory glutamatergic input to other brainstem regions. In any case, the blockade of glutamatergic transmission (KYN or CNQX microinjections) impairs not only the expiratory, but also the inspiratory component of the cough reflex. As to the role of other drugs employed, the effects of DAMGO and muscimol can be accounted for by their action on inhibitory $\mu$-opioid receptors and $\mathrm{GABA}_{\mathrm{A}}$ receptors on the cVRG neurons, while those of baclofen and $\alpha_{2}$-adrenergic agonists could be due to the presynaptic action of $\mathrm{GABA}_{\mathrm{B}}$ receptors and $\alpha_{2}$-adrenergic receptors leading to a reduced release of glutamate (Mutolo et al. 2010, Cinelli et al. 2012, 2013).

All our considerations on the role of cVRG neurons in determining the presence and intensity of both the inspiratory and expiratory components of the cough reflex do not weaken the importance of the NTS in the generation of this defensive reflex, because it remains the primary station of the cough-related afferents, the prevailing locale of the gate control mechanism, and the main neural structure organizing the timing and the intensity of reflex responses. In other words, it seems that there exists a dual control mechanism mainly on the intensity of cough responses as a function of the intensity of the tussigenic stimulus. The control exerted by cVRG neurons appears to be useful to match the intensity of inspiratory and expiratory efforts and to provide a balancing and a fine tuning of the two components. The intensity of the reflex is therefore regulated as a function of the stimulus intensity through NTS function as well as of the intensity of cVRG neuron activation most probably via the activity of other types of neurons brought into action directly by NTS input.

\section{Conflict of Interest}

There is no conflict of interest.

\section{Acknowledgements}

This study was supported by grants from the University of Florence and from the Fondazione Cassa di Risparmio di Firenze, Italy. EC is supported by a Postdoctoral Fellowship from the Dipartimento di Medicina Sperimentale e Clinica, Sezione Scienze Fisiologiche, Università degli Studi di Firenze.

\begin{abstract}
Abbreviations
BötC - Bötzinger Complex; CNQX - 6-cyano-7nitroquinoxaline-2,3-dione; cVRG - caudal ventral respiratory group; DAMGO - [D-Ala ${ }^{2}, \mathrm{~N}-\mathrm{Me}-\mathrm{Phe}^{4}, \mathrm{Gly}^{5}$ ol]-enkephalin; DLH - D,L-homocysteic acid; EAA excitatory amino acid; NMDA - N-methyl-D-aspartic acid; NTS - nucleus tractus solitarii; pFRG - parafacial respiratory group; PiCo - Post-inspiratory Complex; preBötC - preBötzinger Complex; NRA - nucleus retroambigualis; RTN - retrotrapezoid nucleus; KYN kynurenic acid.
\end{abstract}

\section{References}

ANDERSON TM, GARCIA AJ, III, BAERTSCH NA, POLLAK J, BLOOM JC, WEI AD, RAI KG, RAMIREZ JM: A novel excitatory network for the control of breathing. Nature 536: 76-80, 2016. https://doi.org/10.1038/nature18944

ARITA H, KOGO N, KOSHIYA N: Morphological and physiological properties of caudal medullary expiratory neurons of the cat. Brain Res 401: 258-266, 1987. https://doi.org/10.1016/0006-8993(87)91410-7 
BAEKEY DM, MORRIS KF, NUDING SC, SEGERS LS, LINDSEY BG, SHANNON R: Medullary raphe neuron activity is altered during fictive cough in the decerebrate cat. J Appl Physiol 94: 93-100, 2003. https://doi.org/10.1152/japplphysiol.00341.2002

BIANCHI AL, DENAVIT-SAUBIE M, CHAMPAGNAT J: Central control of breathing in mammals: neuronal circuitry, membrane properties, and neurotransmitters. Physiol Rev 75: 1-45, 1995. https://doi.org/10.1152/physrev.1995.75.1.1

BOLSER DC, DAVENPORT PW: Functional organization of the central cough generation mechanism. Pulm Pharmacol Ther 15: 221-225, 2002. https://doi.org/10.1006/pupt.2002.0361

BONGIANNI F, CORDA M, FONTANA GA, PANTALEO T: Chemical activation of caudal medullary expiratory neurones alters the pattern of breathing in the cat. J Physiol 474: 497-507, 1994. https://doi.org/10.1113/jphysiol.1994.sp020040

BONGIANNI F, MUTOLO D, FONTANA GA, PANTALEO T: Discharge patterns of Bötzinger complex neurons during cough in the cat. Am J Physiol Regul Integr Comp Physiol 274: R1015-R1024, 1998. https://doi.org/10.1152/ajpregu.1998.274.4.R1015

BONGIANNI F, MUTOLO D, NARDONE F, PANTALEO T: Ionotropic glutamate receptors mediate excitatory drive to caudal medullary expiratory neurons in the rabbit. Brain Res 1056: 145-157, 2005. https://doi.org/10.1016/j.brainres.2005.07.019

BONHAM AC, JESKE I: Cardiorespiratory effects of DL-homocysteic acid in caudal ventrolateral medulla. Am J Physiol 256: H688-H696, 1989. https://doi.org/10.1152/ajpheart.1989.256.3.H688

CHITRAVANSHI VC, SAPRU HN: Phrenic nerve responses to chemical stimulation of the subregions of ventral medullary respiratory neuronal group in the rat. Brain Res 821: 443-460, 1999. https://doi.org/10.1016/S0006$\underline{\text { 8993(99)01139-7 }}$

CINELLI E, BONGIANNI F, PANTALEO T, MUTOLO D: Modulation of the cough reflex by GABA(A) receptors in the caudal ventral respiratory group of the rabbit. Front Physiol 3: 403, 2012. https://doi.org/10.3389/fphys.2012.00403

CINELLI E, BONGIANNI F, PANTALEO T, MUTOLO D: Suppression of the cough reflex by alpha 2-adrenergic receptor agonists in the rabbit. Physiol Rep 1: e00122, 2013. https://doi.org/10.1002/phy2.122

DEL NEGRO CA, FUNK GD, FELDMAN JL: Breathing matters. Nat Rev Neurosci 19: 351-367, 2018. https://doi.org/10.1038/s41583-018-0003-6

DUTSCHMANN M, HERBERT H: The Kolliker-Fuse nucleus gates the postinspiratory phase of the respiratory cycle to control inspiratory off-switch and upper airway resistance in rat. Eur J Neurosci 24: 1071-1084, 2006. https://doi.org/10.1111/j.1460-9568.2006.04981.x

DUTSCHMANN M, JONES SE, SUBRAMANIAN HH, STANIC D, BAUTISTA TG: The physiological significance of postinspiration in respiratory control. Prog Brain Res 212: 113-130, 2014. https://doi.org/10.1016/B978-0444-63488-7.00007-0

EZURE K: Synaptic connections between medullary respiratory neurons and considerations on the genesis of respiratory rhythm. Prog Neurobiol 35: 429-450, 1990. https://doi.org/10.1016/0301-0082(90)90030-K

FELDMAN JL, DEL NEGRO CA, GRAY PA: Understanding the rhythm of breathing: so near, yet so far. Annu Rev Physiol 75: 423-452, 2013. https://doi.org/10.1146/annurev-physiol-040510-130049

FELDMAN JL, LOEWY AD, SPECK DF: Projections from the ventral respiratory group to phrenic and intercostal motoneurons in cat: an autoradiographic study. J Neurosci 5: 1993-2000, 1985. https://doi.org/10.1523/JNEUROSCI.05-08-01993.1985

GERRITS PO, HOLSTEGE G: Pontine and medullary projections to the nucleus retroambiguus: a wheat germ agglutinin-horseradish peroxidase and autoradiographic tracing study in the cat. J Comp Neurol 373: 173-185, 1996. https://doi.org/10.1002/(SICI)1096-9861(19960916)373:2<173::AID-CNE2>3.0.CO;2-0

HOLSTEGE G: Anatomical study of the final common pathway for vocalization in the cat. J Comp Neurol 284: $242-$ 252, 1989. https://doi.org/10.1002/cne.902840208

HOLSTEGE G, KUYPERS HG: The anatomy of brain stem pathways to the spinal cord in cat. A labeled amino acid tracing study. Prog Brain Res 57: 145-175, 1982. https://doi.org/10.1016/S0079-6123(08)64128-X 
IKEDA K, KAWAKAMI K, ONIMARU H, OKADA Y, YOKOTA S, KOSHIYA N, OKU Y, IIZUKA M, KOIZUMI $\mathrm{H}$ : The respiratory control mechanisms in the brainstem and spinal cord: integrative views of the neuroanatomy and neurophysiology. J Physiol Sci 67: 45-62, 2017. https://doi.org/10.1007/s12576-016-0475-y

ISCOE S: Control of abdominal muscles. Prog Neurobiol 56: 433-506, 1998. https://doi.org/10.1016/S0301$\underline{0082(98) 00046-X}$

JIANG C, LIPSKI J: Extensive monosynaptic inhibition of ventral respiratory group neurons by augmenting neurons in the Bötzinger complex in the cat. Exp Brain Res 81: 639-648, 1990. https://doi.org/10.1007/BF02423514

JONES SE, SAAD M, LEWIS DI, SUBRAMANIAN HH, DUTSCHMANN M: The nucleus retroambiguus as possible site for inspiratory rhythm generation caudal to obex. Respir Physiol Neurobiol. 180: 305-310, 2012. https://doi.org/10.1016/j.resp.2011.12.007

JONES SE, STANIC D, DUTSCHMANN M: Dorsal and ventral aspects of the most caudal medullary reticular formation have differential roles in modulation and formation of the respiratory motor pattern in rat. Brain Struct Funct 221: 4353-4368, 2016. https://doi.org/10.1007/s00429-015-1165-X

KASÉ Y: Antitussive agents and their sites of action. Trends Pharmacol Sci 1: 237-239, 1980. https://doi.org/10.1016/0165-6147(80)90008-5

KORPÁŠ J, TOMORI Z: Cough and Other Respiratory Reflexes. Karger, Basel, 1979.

LIPSKI J, TRZEBSKI A, CHODOBSKA J, KRUK P: Effects of carotid chemoreceptor excitation on medullary expiratory neurons in cats. Respir Physiol 57: 279-291, 1984. https://doi.org/10.1016/0034-5687(84)90077-X

MERRILL EG, LIPSKI J, KUBIN L, FEDORKO L: Origin of the expiratory inhibition of nucleus tractus solitarius inspiratory neurones. Brain Res 263: 43-50, 1983. https://doi.org/10.1016/0006-8993(83)91198-8

MUTOLO D: Brainstem mechanisms underlying the cough reflex and its regulation. Respir Physiol Neurobiol 243: 6076, 2017. https://doi.org/10.1016/j.resp.2017.05.008

MUTOLO D, BONGIANNI F, CINELLI E, PANTALEO T: Depression of cough reflex by microinjections of antitussive agents into caudal ventral respiratory group of the rabbit. J Appl Physiol 109: 1002-1010, 2010. https://doi.org/10.1152/japplphysiol.00406.2010

MUTOLO D, BONGIANNI F, PANTALEO T: Effects of lignocaine blockades and kainic acid lesions in the Bötzinger complex on spontaneous expiratory activity and cough reflex responses in the rabbit. Neurosci Lett 332: 175 179, 2002. https://doi.org/10.1016/S0304-3940(02)00954-0

NEWSOM DAVIS J, PLUM F: Separation of descending spinal pathways to respiratory motoneurons. Exp Neurol 34 : 78-94, 1972. https://doi.org/10.1016/0014-4886(72)90189-6

OKU Y, OKABE A, HAYAKAWA T, OKADA Y: Respiratory neuron group in the high cervical spinal cord $\begin{array}{lllll}\text { discovered by optical imaging. } & \text { Neuroport } & \text { 19: }\end{array}$ https://doi.org/10.1097/WNR.0b013e328318edb5

OKU Y, TANAKA I, EZURE K: Activity of bulbar respiratory neurons during fictive coughing and swallowing in the decerebrate cat. J Physiol 480: 309-324, 1994. https://doi.org/10.1113/jphysiol.1994.sp020361

OTT MM, NUDING SC, SEGERS LS, LINDSEY BG, MORRIS KF: Ventrolateral medullary functional connectivity and the respiratory and central chemoreceptor-evoked modulation of retrotrapezoid-parafacial neurons. J Neurophysiol 105: 2960-2975, 2011. https://doi.org/10.1152/jn.00262.2010

PANTALEO T, BONGIANNI F, MUTOLO D: Central nervous mechanisms of cough. Pulm Pharmacol Ther 15: $227-$ 233, 2002. https://doi.org/10.1006/pupt.2002.0358

PISANSKI A, PAGLIARDINI S: The parafacial respiratory group and the control of active expiration. Respir Physiol Neurobiol 265: 153-160, 2019. https://doi.org/10.1016/j.resp.2018.06.010

POLIACEK I, CORRIE LW, ROSE MJ, WANG C, BOLSER DC: Influence of microinjections of D,L-homocysteic acid into the Bötzinger complex area on the cough reflex in the cat. J Physiol Pharmacol 59 (Suppl 6): 585596, 2008.

POLIACEK I, CORRIE LW, WANG C, ROSE MJ, BOLSER DC: Microinjection of DLH into the region of the caudal ventral respiratory column in the cat: evidence for an endogenous cough-suppressant mechanism. J Appl Physiol 102: 1014-1021, 2007. https://doi.org/10.1152/japplphysiol.00616.2006 
POLIACEK I, ROSE MJ, PITTS TE, MORTENSEN A, CORRIE LW, DAVENPORT PW, BOLSER DC: Central administration of nicotine suppresses tracheobronchial cough in Anaesthetized cats. J Appl Physiol 118: 265 272, 2015. https://doi.org/10.1152/japplphysiol.00075.2014

POLIACEK I, WANG C, CORRIE LW, ROSE MJ, BOLSER DC: Microinjection of codeine into the region of the caudal ventral respiratory column suppresses cough in anaesthetized cats. J Appl Physiol 108: 858-865, 2010. https://doi.org/10.1152/japplphysiol.00783.2009

RICHTER DW, SMITH JC: Respiratory rhythm generation in vivo. Physiology (Bethesda) 29: 58-71, 2014. https://doi.org/10.1152/physiol.00035.2013

SHANNON R, BAEKEY DM, MORRIS KF, LI Z, LINDSEY BG: Functional connectivity among ventrolateral medullary respiratory neurones and responses during fictive cough in the cat. J Physiol 525: 207-224, 2000. https://doi.org/10.1111/j.1469-7793.2000.00207.x

SHANNON R, BAEKEY DM, MORRIS KF, LINDSEY BG: Brainstem respiratory networks and cough. Pulm Pharmacol 9: 343-347, 1996. https://doi.org/10.1006/pulp.1996.0045

SHANNON R, BAEKEY DM, MORRIS KF, NUDING SC, SEGERS LS, LINDSEY BG: Production of reflex cough by brainstem respiratory networks. Pulm Pharmacol Ther 17: 369-376, 2004. https://doi.org/10.1016/j.pupt.2004.09.022

SMITH JC, MORRISON DE, ELLENBERGER HH, OTTO MR, FELDMAN JL: Brainstem projections to the major respiratory neuron populations in the medulla of the cat. J Comp Neurol 281: 69-96, 1989. https://doi.org/10.1002/cne.902810107

SUBRAMANIAN HH, HOLSTEGE G: The nucleus retroambiguus control of respiration. J Neurosci 29: 3824-3832, 2009. https://doi.org/10.1523/JNEUROSCI.0607-09.2009

SUBRAMANIAN HH, HUANG ZG, SILBURN PA, BALNAVE RJ, HOLSTEGE G: The physiological motor patterns produced by neurons in the nucleus retroambiguus in the rat and their modulation by vagal, peripheral chemosensory, and nociceptive stimulation. J Comp Neurol 526: 229-242, 2018. https://doi.org/10.1002/cne.24318

SUGIYAMA Y, SHIBA K, MUKUDAI S, UMEZAKI T, SAKAGUCHI H, HISA Y: Role of the retrotrapezoid nucleus/parafacial respiratory group in coughing and swallowing in guinea pigs. J Neurophysiol 114: 17921805, 2015. https://doi.org/10.1152/jn.00332.2015

VON EULER C: Brain stem mechanisms for generation and control of breathing pattern. In: Handbook of Physiology. The Respiratory System. Control of Breathing. NS CHERNIACK, JG WIDDICOMBE (eds), American Physiological Society, Bethesda, MA, 1986, pp 1-67.

WIDDICOMBE JG: Reflexes from the upper respiratory tract. In: Handbook of Physiology. The Respiratory System. Control of Breathing. NS CHERNIACK, JG WIDDICOMBE (eds), American Physiological Society, Bethesda, MD, 1986, pp 363-394.

ZHENG Y, RICHE D, REKLING JC, FOUTZ AS, DENAVIT-SAUBIE M: Brainstem neurons projecting to the rostral ventral respiratory group (VRG) in the medulla oblongata of the rat revealed by co-application of NMDA and biocytin. Brain Res 782: 113-125, 1998. https://doi.org/10.1016/S0006-8993(97)01251-1 